\title{
Implementation and Evaluation of a \\ Nutrition Risk Screening Tool in a Rehab Setting
}

\author{
Amanda Beales, RD, MAN, CDE'; Savannah Black, BASc, MPH'; Rebecca Brown, RD'; Anthea Tonelli, \\ $R D^{1}$; Heidi Wilk, $R D^{1}$; Samantha Riddell, $R D^{1}$; Kara Dawson, $R D^{1}$; Jennifer Whitelaw, $R D^{1}$ \\ ${ }^{1}$ Toronto Rehabilitation Institute, University Health Network, Toronto, Ontario, Canada \\ 2Dalla Lana School of Public Health, University of Toronto, Toronto, Ontario, Canada
}

Purpose

The purpose of this project was to implement a nutrition risk screening tool for all inpatient rehab units at Toronto Rehabilitation Institute (TRI) and to complete a process evaluation on its use.

\section{Background}

A review of best practice indicates that systematic nutrition risk screening should be completed for all new admissions to ensure that patients at high nutrition risk are identified in a timely manner. ${ }^{1}$ An 'Identification of Nutrition Risk Level' (INRL) tool was developed over 10 years ago at TRI with a process of nursing completion within $72 \mathrm{hrs}$ of patient admission, to help Registered Dietitians (RDs) triage patients based on nutrition risk. Due to inconsistent completion and accuracy, the need for a revised tool became evident.

\section{Process}

An updated nutrition risk screening tool and process was created and implemented, guided by the TRI Clinical Best Practice Process which consists of a patient needs assessment, review of present practice, review of best practice, gap analysis, preparation, implementation and evaluation. ${ }^{2}$ The updated tool incorporated the Canadian Nutrition Screening Tool along with additional criteria regarding common needs for RD intervention in rehab and was designed to be completed by nursing within $24 \mathrm{hrs}$ of patient admission.

\section{Results}

Nursing education was provided for 93 inpatient rehab nurses. Completion rates for new admissions improved from an average of $47 \%$ to $87 \%$. $97 \%$ were completed within $24 \mathrm{hrs}$ of admission. The accuracy of information on the completed tools also improved, from $\sim 50-80 \%$ accurate to $90 \%$.

\section{Table 1: Original INRL Tool vs. Updated Nutrition} Risk Tool

\begin{tabular}{|c|c|}
\hline INRL Tool & Updated Tool \\
\hline Used in 7/11 inpatient units & Used in 11/11 inpatient units \\
\hline $\begin{array}{c}\text { Completed for } 47 \% \text { of new } \\
\text { admissions }\end{array}$ & $\begin{array}{c}\text { Completed for } 87 \% \text { of new } \\
\text { admissions }\end{array}$ \\
\hline Accuracy of completion: & Accuracy of completion: \\
$90 \%$ & $90 \%$ \\
\end{tabular}

Table 2: Top Nutrition Risk Factors Identified

\begin{tabular}{|c|c|c|c|}
\hline & $\begin{array}{c}\text { Unintended } \\
\text { Weight loss }\end{array}$ & $\begin{array}{c}\text { Other } \\
\text { nutrition- } \\
\text { related } \\
\text { concerns* }\end{array}$ & $\begin{array}{c}\text { Eating less than } \\
\text { usual for more } \\
\text { than 1 week }\end{array}$ \\
\hline $\begin{array}{c}\text { Across TRI } \\
\text { (n=80 } \\
\text { tools) }\end{array}$ & $31 \%$ & $27 \%$ & $20 \%$ \\
\hline
\end{tabular}

*Most common 'Other nutrition-related concerns' (freetext option for nursing to communicate to RD): Diet order requests, dysphagia, wounds, and food allergies.

\section{Recommendations}

Measures such as on-going training and auditing are needed for sustainability of this positive change, the next step in the TRI Clinical Best Practice Process. ${ }^{2}$ Moreover, an outcome evaluation will be helpful to further understand the long-term impact of the tool on dietetic practice and patient care. ${ }^{3}$

\section{Significance to the Field of Dietetics}

There are currently no validated screening tools developed for the rehab patient population. ${ }^{4}$ The positive results observed from the present screening tool may help bridge the gap regarding systematic nutrition risk screening among rehab patients.

\section{References}

${ }^{1}$ Mueller C, Compher C, et al (2011). A.S.P.E.N. Clinical Guidelines. Journal of Parenteral and Enteral Nutrition, 35(1):16-24.

${ }^{2}$ McGlynn, M., Solway, S., Lowe, M., Howe, J. A., Hebert, D., \& Velji, K. (2011). Organizational model and process for clinical best practice in rehabilitation and complex continuing care. Healthcare quarterly (Toronto, Ont.), 14(1), 62-69.

${ }^{3}$ Eglseer, D., Schoberer, D., Halfens, R., \& Lohrmann, C. (2019). The impact of using a malnutrition screening tool in a hospital setting: a mixed methods study. European journal of clinical nutrition, 73(2), 284.

${ }^{4}$ Marshall, S., Young, A., Bauer, J., \& Isenring, E. (2016). Malnutrition in geriatric rehabilitation: prevalence, patient outcomes, and criterion validity of the scored patient-generated subjective global assessment and the mini nutritional assessment. Journal of the Academy of Nutrition and Dietetics, 116(5), 785-794.

Acknowledgments We would like to thank the TRI Clinical Nutrition Assistants, Vicky Pun, Joey Huang and May Hua for their support of this project, as well as the entire inpatient nursing team. 